\title{
Simulation of Flood Detection System Using Atmega 8535 Microcontroller
}

\author{
Reza Zubaedah ${ }^{1}$, Stanly Hence Dolfi Loppies ${ }^{2}$, Nasra Pratama Putra ${ }^{3}$ \\ Information Systems Department \\ Universitas Musamus \\ Merauke, Indonesia \\ ${ }^{1}$ reza@unmus.ac.id, ${ }^{2}$ stanly@unmus.ac.id, ${ }^{3}$ nasrapratama@unmus.ac.id
}

\begin{abstract}
Flood disasters are usually caused by the rising of sea water and high rainfall resulting in high water discharge. One way to reduce the impact of losses caused by standing water is to measure the height of the water discharge. An ultrasonic sensor that is based on a microcontroller can be used to measure the height of the water discharge. This water level monitoring system is carried out by implementing a microcontroller-based ultrasonic sensor. The use of this system is expected by the writer to be a water level detection simulation where the system works by giving an alarm when the height of the water discharge crosses the limit set on the system. When the height of the water discharge exceeds the limit, the system will provide information in the form of an alarm sound and the system display that is initially green turns red.
\end{abstract}

Keywords-Flood detection system; water discharge heigh; ultrasonic sensor; microcontroller

\section{INTRODUCTION}

The southern regions of Papua, Merauke, Mappi and Asmat, have low and cloudy plains with a slope of $0-3 \%$ where the southern regions are prone to landslides, floods and sea water intrusion (Regional Tourism Promotion Board - BPPD). One of the disasters that often occurs in Merauke Regency is a flood disaster. Floods are often caused by the rising of sea levels and high rainfall.

The influence of high rainfall causes the flow of water on the earth's surface and the speed of the water flow is not proportional to the amount of drainage and the speed of water flow to the river or canal and then to the reservoir in the form of reservoirs or seas resulting in overflow of water in various areas in several places. The waterlogging can be caused by silting of the river and waste that is disposed of by people who live around the river and the impact of the development of the city area which results in the lack of water catchment areas.

A number of points prone to flooding in Merauke Regency include Payum, Mbuti, Ndalir, Okaba, Urumb and Waan Districts, where these areas have experienced floods and did not rule out the possibility of recurrence (Indonesian National Board for Disaster Management - BNPB).

One way to reduce the impact of losses caused by standing water is to find out the surface height and the water discharge. For this reason, it is necessary to measure the height of the water discharge which can automatically provide information when there is an increase in water discharge. Detecting water level can be done using Doppler radar, but it requires complicated hardware design. This method is not only complicated but also requires considerable costs. Another alternative that is more economical to detect the water level is carried out using an ultrasonic sensor based on a microcontroller [1].

The height and discharge measurement system can be monitored and calculated, and it gives a signal if the excess height matches the computerized (automatic) height. Microcontrollers equipped with ultrasonic sensors will be used to measure water level and water discharge. The sensor approaches the distance from the sensor to the surface of the water so there is no need to do it with physical contact between the sensor and water.

\section{THEORETICAL REVIEW}

\section{A. Ultrasonic Sensor}

The ultrasonic parallax PING sensor is able to detect objects from a range of $3 \mathrm{~cm}$ to $300 \mathrm{~cm}$. This sensor works by transmitting the ultrasonic signal with a frequency of $40 \mathrm{kHz}$ and receiving its reflection. The working principle of PING sensor is like Figure 1. where the working principle of PING sensor will send a signal (ultrasonic wave) when the microcontroller gives a trigger pulse (high pulse), then the PING sensor will emit ultrasonic waves.

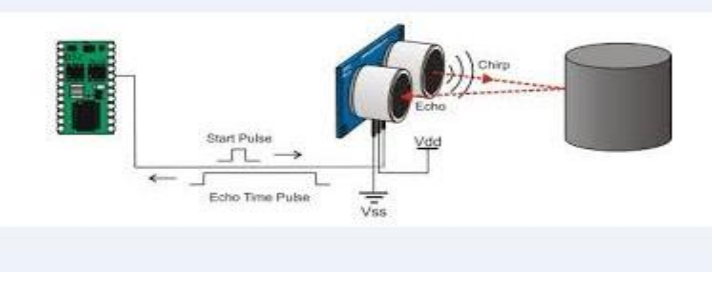

Fig. 1. Working Principle of ultrasonic sensors [2]

\section{B. Microcontroller}

Microcontroller is a digital tool that has input and output as well as control with programs that can be written and deleted specifically. The microcontroller is a single chip 
which includes CPU, ROM, RAM, I/O, clock and other internal equipment [3].

\section{Information system}

An information system is a collection of hardware and software designed to transform data into useful forms of information [4]. In the water discharge detection system the role of softawe and hardware is very important to support each other so that the system can run according to what has been designed.

\section{METHODOLOGY AND SYSTEM DESIGN}

\section{A. Non Functional Needs Analysis}

In the process of making a simulation of the measurement of water discharge height, several software and hardware components will be used to support the system design and manufacturing process, namely:

\section{1) Hardware}

Analysis of hardware requirements used to make high water discharge simulations:

- 14 "Wide XGA LCD panel LED monitor

- Intel inside-Corei3 processor

- Keyboard, Mouse, CDR ROM and CPU

- ATMega 8535 microcontroller

- Ranger Finder ultrasonic sensor

2) Software

Analysis of software requirements used to make high water discharge simulations:

- Windows 7 Operating System

- $\quad$ Borland Delphi 7 interface design and programming

- Bascom AVR programming language to calculate the height of the water discharge

\section{B. Hardware block diagram}

In the system, the microcontroller is used as the main control unit which contains programs to monitor levels, including the LCD display and PING sensor clock input. The hardware design can be seen in Figure 2.

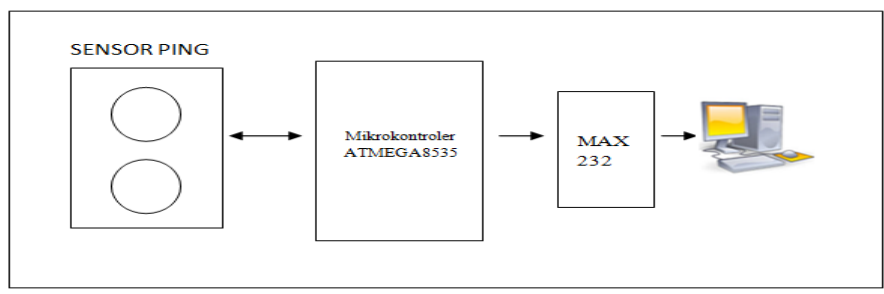

Fig. 2. Hardware design for measuring water discharge height

While the use of ports on the Atmega 8535 circuit can be seen in Table 1 .
TABLE I. THE USE OF PORTS ON ATMEGA8535

\begin{tabular}{|l|l|l|}
\hline \multicolumn{2}{|c|}{ PORT ATMEGA8535 } & \multicolumn{1}{c|}{ Function } \\
\hline Port A & PORTA.0 - PORTA.7 & LCD \\
\hline Port B & PORTB. 0 & PING $^{\mathrm{TM}}$ Sensor \\
\hline Port D & PORTD. $0-1$ & To Computers \\
\hline
\end{tabular}

\section{User Interface Design}

The user interface design is very important to explain every DFD visually so that it is easy to understand and easy in the implementation process in the system. The design of the user interface can be seen in Figure 3.

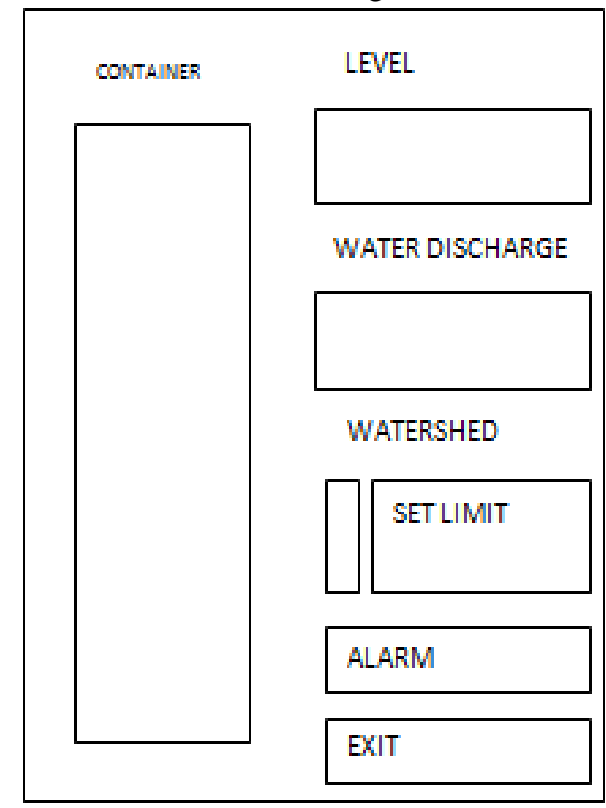

Fig. 3. User interface design

\section{RESULTS AND DISCUSSION}

\section{A. System Implementation}

The system implementation stage is the stage where the system will be operated and realising the system based on the design that has been made. The system that has been designed at the previous stage is applied in the form of software and hardware. With this application, the system can be operated and used as needed. The implementation stage is also the system implementation phase that will be carried out if the system is approved including the programs that have been made at the system design stage so that they are ready to operate. Implementation in this application uses software and hardware design.

\section{B. Test Results}

\section{1) Testing the RS232 Converter Module}

This test is intended to test whether the converter can be used to communicate between the microcontroller and the computer. This test is done by connecting the serial data cable from the device to the computer, then pin 11 and pin 12 of the RS232 converter are connected so that a loop occurs. After that, run the HyperTerminal application 
program in Windows. Press any key, if the key pressed is displayed on the monitor screen, the converter can be used as can be seen in Figure 4.

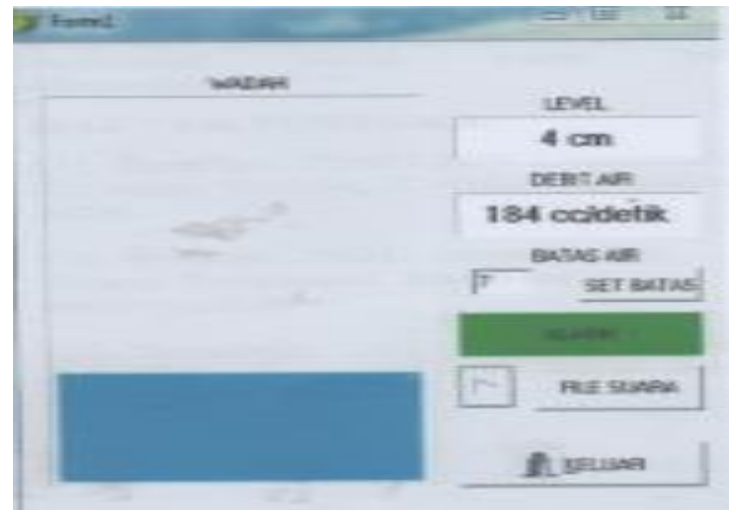

Fig. 4. Testing of serial data cables

2) Testing the Ultrasonic Sensors and Interface Display

Ultrasonic sensor testing is done by measuring the distance from the sensor using hands and water media. Sensor readings are limited to a height of $4 \mathrm{~cm}-25 \mathrm{~cm}$ and the object to be measured is a buoy so that water level can be obtained.Testing using hand and testing watr level abve 7 $\mathrm{cm}$ can sse in Figure 5 and Figure 6. The Alarm will sound when height limir over for water limit. When the alarm sounds, the display on the user interface will change from the beginning, the white color will be red, indicating that the water has exceeded the predetermined limit.

a) Ultrasonic sensor testing is done with hands and water media

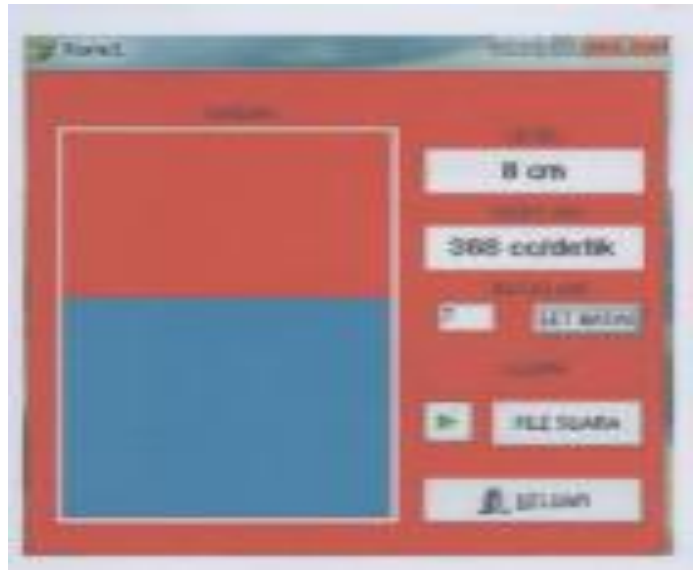

Fig. 5. User Interface Display

Description:

In the picture above, after testing using hand and water. the water level limit is set with a height limit of $7 \mathrm{~cm}$. the example we input uses a $4 \mathrm{~cm}$ discharge height so that we will get a high level of $4 \mathrm{~cm}$ calculation and $144 \mathrm{cc} /$ second of water discharge and still within the specified normal limit. So the alarm doesn't sound. b) Testing with a water level above $7 \mathrm{~cm}$ and an alarm will sound

When the water level is above $7 \mathrm{~cm}$ on the system, it can be seen by the color changing of the form which is originally white and when the water level exceeds $7 \mathrm{~cm}$ it will turn red. In addition, an alarm will sound to indicate that the water has exceeded a predetermined limit of $7 \mathrm{~cm}$. This can be seen in Figure 6.

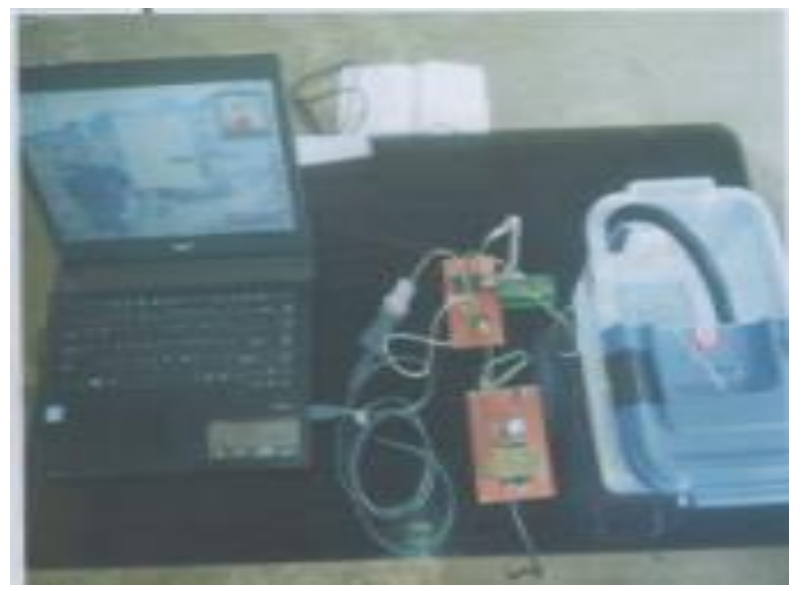

Fig. 6. User interface with an alarm

\section{Description:}

In Figure 6 the test was carried out with a height limit of 7 $\mathrm{cm}$ and a calculation of the height level with a height of 8 $\mathrm{cm}$ and a water discharge of $368 \mathrm{cc} / \mathrm{second}$ was obtained, then the initial display of the program is automatically red and the alarm sounds because the water level has exceeded the specified limit of $7 \mathrm{~cm}$.

\section{CONCLUSION}

The simulation application to measure the height of the water discharge generated can monitor the height of the water discharge at any time and provide a warning sign in the form of alarm information that sounds when the water discharge exceeds the set height of the height limit. Information on the height of the water discharge is shown through the green color where the water level indicates normal and red indicates the water level is over the specified limit so that the alarm will sound automatically.

\section{ACKNOWLEDGMENT}

We thank Universitas Musamus for facilities, supports, and publications.

\section{REFERENCES}

[1] Taufiqurrahman, A. Basuki, and Y. Albana Y. 2013. "Telemetry System Design for Ultrasonic Based Water Level Measurement”, Proceed. Conf. on Smart Gr. Technol. in Electr. and Inf. Syst. [internet], Bali (ID), pp. 125 -130, 2013.

[2] Parralax, Ultrasonic Distance Sensor, California: Parallax, 2006.

[3] Sumardi, Microcontroler R8C/13, Jakarta: PT Elex Media Komputindo, 2013.

[4] Witarto, Understanding Information Systems. Bandung: Informatika, 2004. 